\title{
Ectopic Parathyroid Adenoma in the Carotid Sheath
}

\author{
Christopher D. Sanders, Jared D. Kirkland, and Ely A. Wolin \\ David Grant USAF Medical Center, Travis Air Force Base, Fairfield, California
}

Primary hyperparathyroidism is predominantly caused by a single parathyroid adenoma. Knowledge of normal and ectopic locations of parathyroid glands is crucial to help guide surgeons who plan targeted unilateral parathyroidectomy to reduce surgical time and risk. We describe a female patient with clinical primary hyperparathyroidism who underwent a failed initial parathyroidectomy, with subsequent imaging localizing an ectopic parathyroid adenoma in the carotid sheath.

Key Words: hyperparathyroidism; ectopic parathyroid adenoma; 99mTc-sestamibi

J Nucl Med Technol 2016; 44:201-202

DOI: 10.2967/jnmt.115.170993

iven that ectopic parathyroid glands are not uncommon in the setting of primary hyperparathyroidism, preoperative localization is critical to the current minimally invasive approaches toward surgical excision. Knowledge of ectopic locations and appropriate imaging guidelines is imperative.

\section{CASE REPORT}

Our patient was clinically diagnosed with primary hyperparathyroidism after a workup for incidental hypercalcemia. Dual-phase ${ }^{99 \mathrm{~m} T c-s e s t a m i b i}$ scintigraphy with early SPECT/ CT demonstrated uptake posterior and lateral to the superior left thyroid (Figs. 1 and 2). The findings of neck ultrasound were unremarkable.

Excision of the left superior parathyroid gland led to no change in intraoperative parathyroid levels. The surgeon proceeded with left hemithyroidectomy and bilateral explorative dissection, with no abnormal tissue found on pathologic examination.

Postoperative MRI did not prospectively identify a parathyroid adenoma. Repeated dual-phase parathyroid scintigraphy confirmed persistence of the adenoma. Repeated SPECT coregistered with dedicated neck CT localized the adenoma to the left carotid sheath (Figs. 3 and 4).

Repeated surgery removed a pathology-proven parathyroid adenoma from the left carotid sheath.

Received Dec. 8, 2015; revision accepted Jan. 27, 2016.

For correspondence or reprints contact: Christopher D. Sanders, David Grant USAF Medical Center, 101 Bodin Circle, Fairfield, CA 94535.

E-mail: christopher.sanders.15@us.af.mil

Published online Feb. 4, 2016.

COPYRIGHT (C) 2016 by the Society of Nuclear Medicine and Molecular Imaging, Inc.

\section{DISCUSSION}

Primary hyperparathyroidism is a clinical diagnosis based primarily on laboratory results, usually in the fifth to seventh decades of life (1). Hypercalcemia, the primary clinical abnormality, can present with numerous symptoms, including bone or abdominal pain, nephrolithiasis, and psychiatric imbalances (1). Etiologies include a single parathyroid adenoma, multiglandular hyperplasia, multiple adenomas, and, rarely, parathyroid carcinomas (1). Surgical excision of abnormal parathyroid

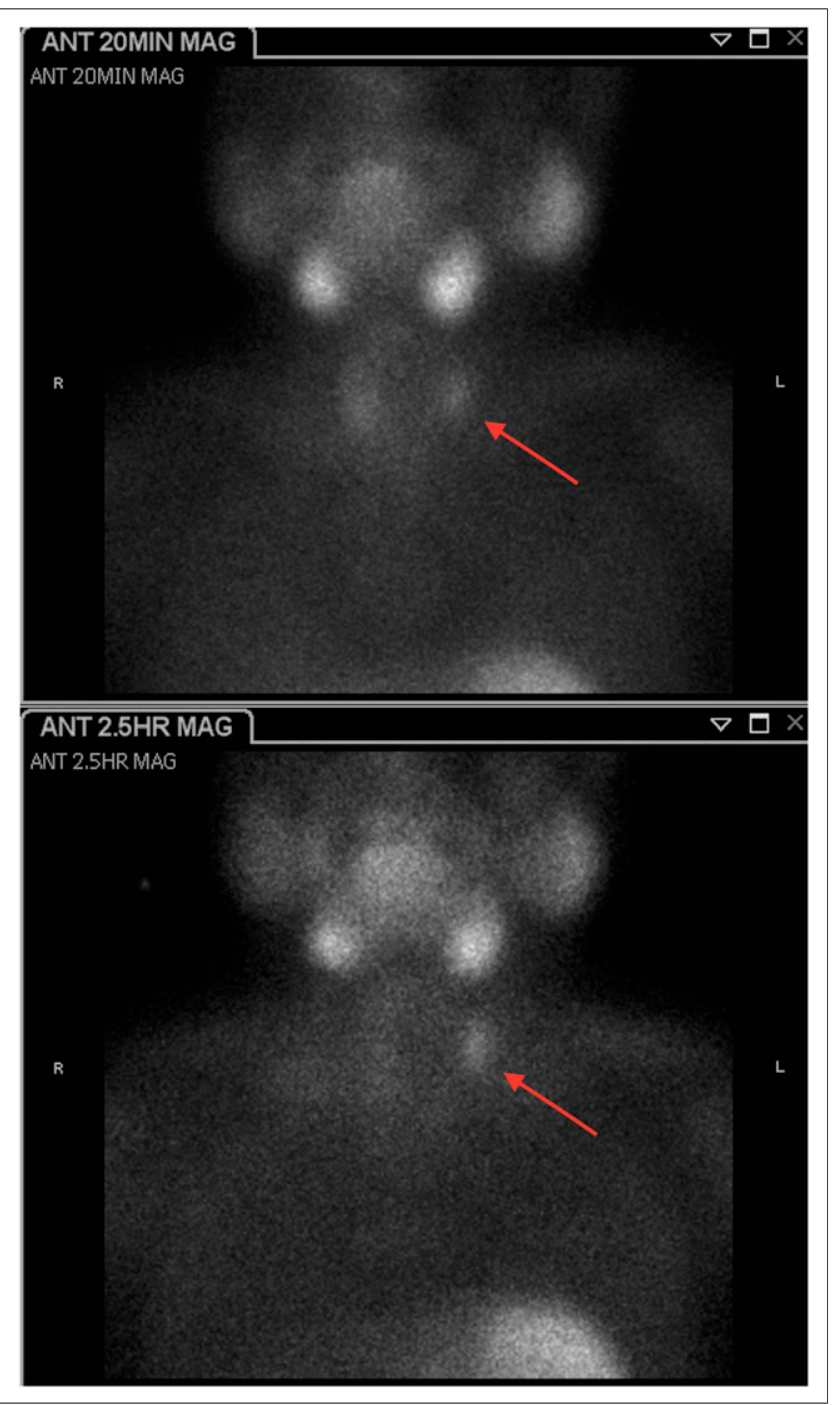

FIGURE 1. Anterior 20-min (top) and 2.5-h (bottom) ${ }^{99 m}$ Tcsestamibi images demonstrate persistent focal uptake in left neck. MAG = magnified. 


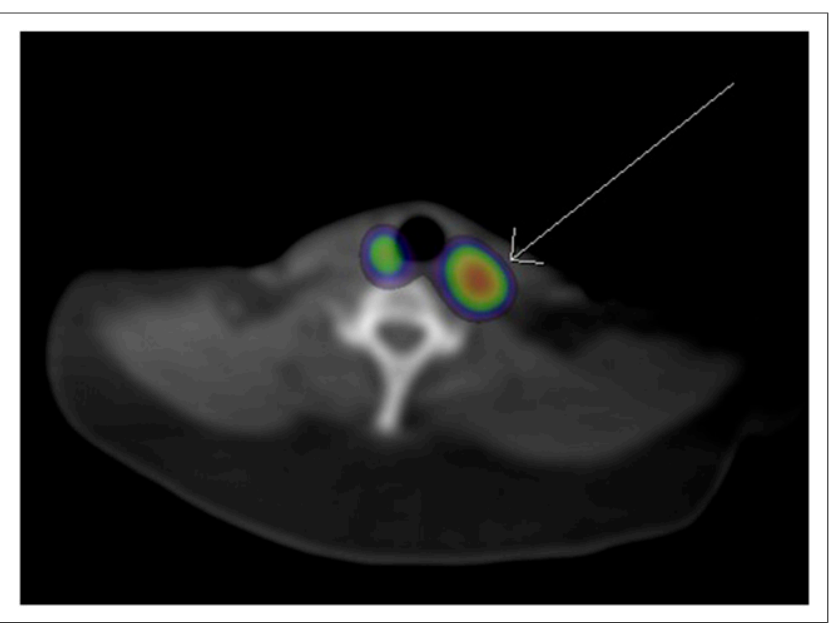

FIGURE 2. SPECT/CT data localize uptake posterior and lateral to superior left thyroid gland.

tissue is usually curative. Historically, bilateral cervical dissection has been performed with 95\% success $(1)$. Preoperative imaging localization, however, allows for focused surgeries, reducing procedure length and risk (2).

Usually, 2 superior and 2 inferior parathyroid glands are immediately posterior to the thyroid. Ectopic parathyroid glands exist in numerous locations between mouth and diaphragm, with a frequency of $6 \%-16 \%$ (3). Ectopia in the carotid sheath, as occurred in our patient, is reported in less than $1 \%$ of cases (2).

Our institution performs a dual-phase ${ }^{99 \mathrm{~m}} \mathrm{Tc}$-sestamibi protocol, with planar images obtained at 20 and $150 \mathrm{~min}$, plus SPECT/CT at $20 \mathrm{~min}$ for improved localization (4). The initial examination was limited by the reduced spatial resolution of the coregistered low-dose cone-beam CT scan; subsequent

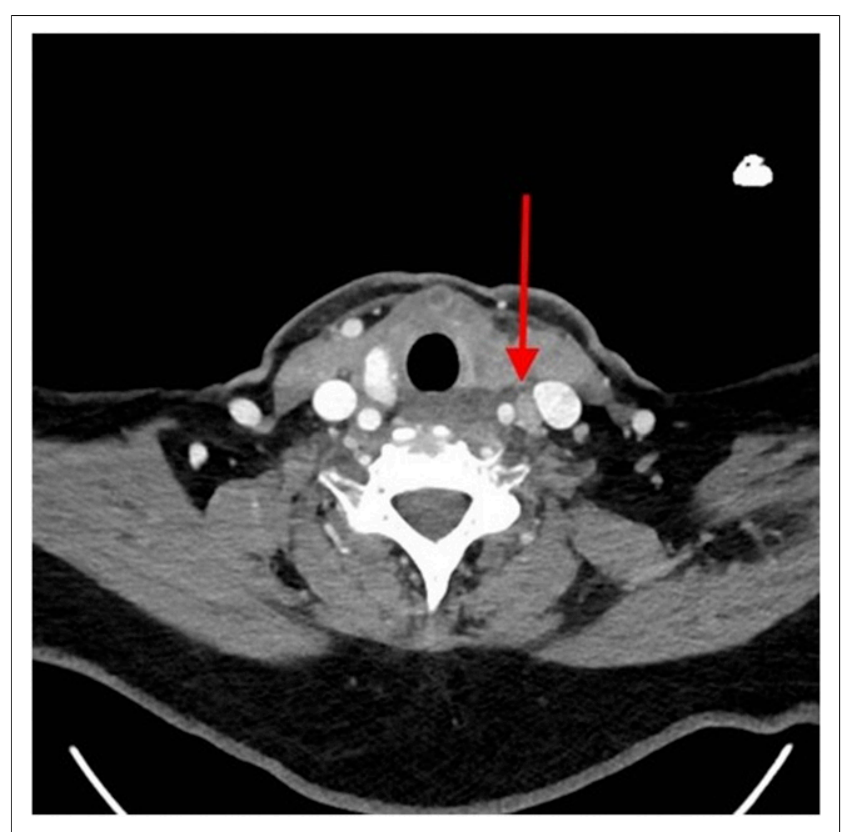

FIGURE 3. Contrast-enhanced CT demonstrates soft-tissue lesion in left carotid sheath.

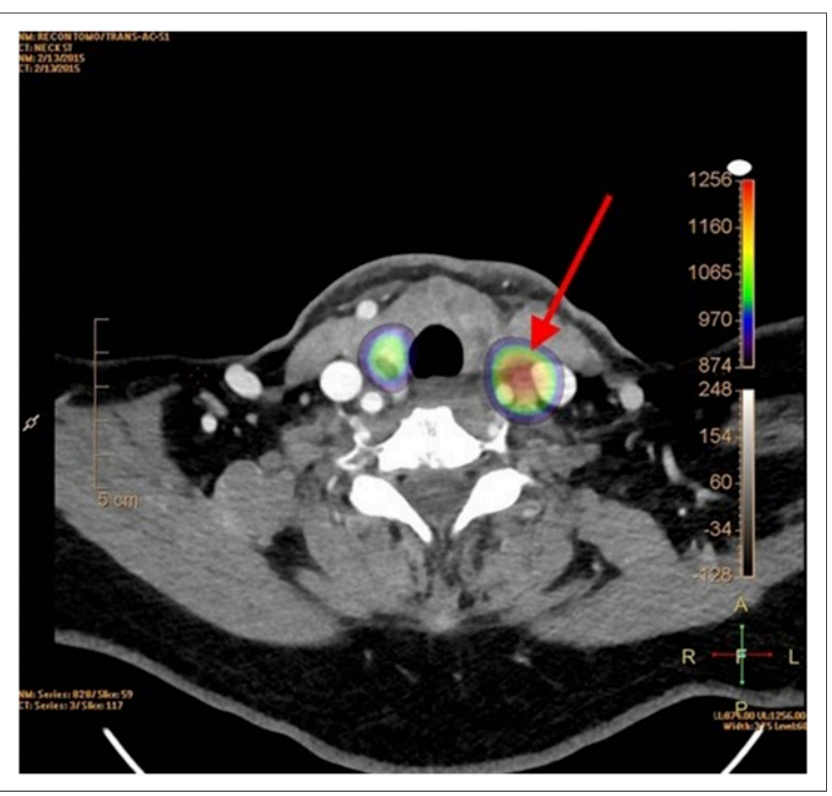

FIGURE 4. Fused SPECT/high-resolution CT localizes uptake to soft-tissue lesion in left carotid sheath.

coregistration with high-resolution CT proved invaluable. Four-dimensional CT, along with ultrasound and MRI, can also improve preoperative localization (5).

\section{CONCLUSION}

Because focused unilateral parathyroidectomy is curative in most cases of primary hyperparathyroidism, with less surgical time and risk than nontargeted surgery, preoperative localization is crucial. Frequently, the clinical question focuses on whether there is an adenoma-a question readily answered with planar scintigraphy alone. However, the better anatomic localization and spatial resolution provided by advanced imaging is extremely helpful. The initial surgical failure in this case may have been prevented if the initial CT scan had been of higher resolution or if ectopia had been suspected because of the location of the parathyroid adenoma - posterior and lateral to the thyroid.

\section{DISCLOSURE}

No potential conflict of interest relevant to this article was reported. The views expressed in this paper are those of the authors and do not reflect the official position of the U.S. Government, the Department of Defense, or the Department of the Air Force.

\section{REFERENCES}

1. Johnson NA, Tublin ME, Ogilvie JB. Parathyroid imaging: technique and role in the preoperative evaluation of primary hyperparathyroidism. AJR. 2007;188: 1706-1715.

2. Eslamy HK, Ziessman HA. Parathyroid scintigraphy in patients with primary hyperparathyroidism: ${ }^{99 \mathrm{~m}} \mathrm{Tc}$ sestamibi SPECT and SPECT/CT. Radiographics. 2008;28:1461-1476.

3. Roy M, Mazeh H, Chen H, Sippel RS. Incidence and localization of ectopic parathyroid adenomas in previously unexplored patients. World J Surg. 2013;37:102-106.

4. Greenspan BS, Dillehay G, Intenzo C, et al. SNM practice guideline for parathyroid scintigraphy 4.0. J Nucl Med Technol. 2012;40:111-118.

5. Smith JR, Oates E. Radionuclide imaging of the parathyroid glands: patterns, pearls, and pitfalls. Radiographics. 2004;24:1101-1115. 